\title{
Hyperostosis frontalis interna, acromegaly and hyperprolactinaemia
}

\author{
James D. Fulton, John Shand' ${ }^{1}$, David Ritchie' and Janice McGhee \\ Departments of Geriatric Medicine and ${ }^{1}$ Radiology, Stobhill General Hospital, Glasgow G21 2UW, UK.
}

\begin{abstract}
Summary: The association between hyperostosis frontalis interna (HFI), acromegaly and hyperprolactinaemia was investigated. Thirty six acromegalic patients, of whom 19 had hyperprolactinaemia, were compared with 36 randomly-selected, age-sex matched controls. There was a higher prevalence of HFI in the skull X-rays of the acromegalic cohort $(P=0.0002)$ when compared to the control group. This difference was apparent in both men $(P=0.01)$ and women $(P=0.01)$. Acromegalic patients with hyperprolactinaemia also expressed HFI in a higher proportion of individuals than the control group $(P=0.0001)$. Intra- and interobserver variability was assessed and concordance with $100 \%$ and $97 \%$ in the moderate and severe HFI sub-groups. The following sub-group analysis was undertaken: acromegalics and those acromegalics with hyperprolactinaemia were compared with the controls and a highly significant distinction was confirmed $(P=0.0007$ and $P=0.00001$ respectively $)$. A relationship between HFI severity and the patient's age was noted in both male and female acromegalics. Also, the severity of HFI appeared related to disease duration in female acromegalics.

The cause of HFI remains unknown but appears to be strongly associated with acromegaly, particularly in the presence of co-existent hyperprolactinaemia. The association may have symptomatic significance and the presence of HFI should be confirmed or refuted in all patients with acromegaly.
\end{abstract}

\section{Introduction}

Hyperostosis frontalis interna (HFI) is a common, often incidental, finding on a skull X-ray. It is considered to occur more frequently in women with a quoted female:male sex ratio of $9: 1 .^{1}$ It has a peak incidence in the 40-60 year age group, in which group $15-20 \%$ of women are reported to have some evidence of HFI.

Despite its frequent occurrence, the exact cause of HFI remains unknown. Many researchers have attempted to link its occurrence with metabolic or endocrine abnormalities. In 1978, Koev and colleagues $^{2}$ demonstrated that patients with the Morgagni-Stewart-Morel (MSM) syndrome, (HFI, virilism, obesity, headaches and various neuropsychological features), had both an elevated basal growth hormone level and a failure to suppress this raised growth hormone level with oral glucose loading. A relationship between HFI and acromegaly has also been proposed by Littlejohn $e t$ $a l^{3}$ in their studies of the association between diffuse idiopathic skeletal hyperostosis (DISH) and acromegaly. Also, both the MSM syndrome and HFI itself have been associated with hyperprolactinaemia. In those with normal basal serum

Correspondence: J.D. Fulton, M.R.C.P.

Accepted: 4 August 1989 prolactin (PRL) levels, abnormal PRL mobilization in response to stress tests ${ }^{4}$ has been demonstrated.

As a substantial proportion of acromegalic patients have co-existent hyperprolactinaemia, a joint retrospective endocrine and radiological study was undertaken to investigate the association between the relatively common finding of HFI and the comparatively rare findings of acromegaly with or without hyperprolactinaemia.

\section{Patients and methods}

The study population consisted of 36 acromegalic patients (16 male, 20 female) identified from the Endocrinology Units of Stobhill Hospital and the Western Infirmary in Glasgow. The mean age of the male patients was 55.3 years (range $30-83$ years), and of the female patients was 59.0 years (range 36-81 years). Diagnosis of acromegaly had been established clinically, biochemically, radiologically and often histologically. Skull $\mathrm{X}$-rays and clinical details were obtained for all patients. In addition, skull $\mathrm{X}$-rays were obtained for 36 age-sex matched control patients randomly selected from patients attending the Stobhill General Hospital Casualty Department, with head trauma insufficiently severe to have caused a fracture. 
The skull X-rays of both the acromegalic and the control patients were examined blind on 2 separate occasions by 2 independent trained observers (J.S. and D.R.). HFI was assessed according to the criteria proposed by Littlejohn ${ }^{3}$ : nil $(\mathrm{N})$ : no new bone formation; mild (MI): early endosteal bone on inner table of skull; moderate (MO): more advanced endosteal bone with bosselated appearance; severe (S): changes extending beyond the midline with much irregularity and increased thickness.

Retrospective analysis of the patients' casenotes was also undertaken. Data relating to endocrine history, disease duration, hormone levels, mode(s) of therapy, bone biochemistry and arthropometric details were recorded. Insulin levels were not consistently available. PRL levels were recorded and were judged to be elevated significantly when 2 or more recordings of concentrations above $450 \mathrm{U} / 1$ (normal range 0-300 U/1) were available.

Patients were excluded on the grounds of inadequate clinical or radiological details. Patients who had undergone craniotomy were also excluded as the changes of HFI could not be reliably graded in the presence of the normal post-surgical osseous changes.

Statistical analysis used the chi-square test, with Yates correction applied.

\section{Results}

Seventy two per cent of patients with acromegaly had evidence of HFI on skull X-rays, compared to $25 \%$ of the control group $(P=0.0002)$. This relationship was significant for both men $(P=0.01)$ and women $(P=0.01)$. Nineteen patients with acromegaly were regarded as having unequivocal hyperprolactinaemia. Of these, 12 had PRL levels in the range 450-1000 U/1 and 7 had PRL levels ranging from $1050-3900 \mathrm{U} / \mathrm{l}$. Two additional individuals had one record of PRL raised to between 300-450 U/1, but were classified for the purpose of this study and with the information available, as 'reactive hyperprolactinaemia'. Sixteen of these patients with unequivocal hyperprolactinaemia had HFI. Those acromegalic patients with hyperprolactinaemia also had evidence of HFI in a significantly higher proportion of individuals than the control group (Tables I, II and III).

Assessment of intra-observer and inter-observer variation was also undertaken to assess the accuracy of the criteria applied to the diagnosis of HFI. Intra-observer assessment recorded $81 \%$ concordance with all $19 \%$ disagreeing answers being in the normal and mild HFI categories. The accuracy of the criteria applied to moderate and severe $\mathrm{HFI}$ was $100 \%$. Inter-observer concordance was $88 \%$, with only $3 \%$ of the disagreeing answers
Table I Comparision of the skull X-rays of the acromegalic cohort with the skull X-rays of the-control patients

\begin{tabular}{lcrcc}
\hline $\begin{array}{l}\text { Skull X-ray } \\
\text { value }\end{array}$ & Normal & HFI & $\begin{array}{c}\text { Chi } \\
\text { square }\end{array}$ & $\begin{array}{c}P \\
\text { value }\end{array}$ \\
\hline Acromegalic : Total & 10 & 26 & 14.23 & 0.0002 \\
Control : Total & 27 & 9 & & \\
Acromegalic: Male & 6 & 10 & 6.53 & 0.0106 \\
Control : Male & 14 & 2 & & \\
Acromegalic : Female & 4 & 16 & 6.55 & 0.0105 \\
Control : Female & 13 & 7 & & \\
\hline
\end{tabular}

Table II Comparision of the skull X-rays of those acromegalics with hyperprolactinamia with the skull $\mathrm{X}$-rays of the controls

\begin{tabular}{|c|c|c|c|c|}
\hline $\begin{array}{l}\text { Skull X-ray } \\
\text { value }\end{array}$ & Normal & $H F I$ & $\begin{array}{c}\text { Chi } \\
\text { square }\end{array}$ & $P$ \\
\hline Acromegaly : Total & 3 & 16 & 15.28 & 0.0001 \\
\hline Control : Total & 27 & 9 & & \\
\hline Acromegaly : Male & 1 & 5 & 7.09 & 0.0077 \\
\hline Control : Male & 14 & 2 & & \\
\hline Acromegaly : Female & 2 & 11 & 5.59 & 0.0147 \\
\hline Control : Female & 13 & 7 & & \\
\hline
\end{tabular}

in the moderate and severe HFI categories, thus suggesting $\mathbf{9 7 \%}$ concordance in established HFI.

There appeared to be some variability in the subjective distinction between normal skull $\mathrm{X}$-rays and mild HFI. Therefore, as the accuracy of describing moderate and severe HFI was high, sub-group analysis was undertaken with the moderate and severe HFI cohorts. Acromegalics with normal PRL levels (with moderate/severe HFI) and those acromegalics with hyperprolactinaemia, also with moderate and severe HFI, were compared with controls, similarly with moderate and severe HFI. A highly significant distinction was demonstrated between the two groups confirming that the presence of definite, established HFI is associated with acromegaly and, in particular, with that sub-group of acromegalics who have co-existent hyperprolactinaemia.

Our observed female:male ratio in acromegalics with HFI was 1.6:1. There was, in addition, a relationship between the severity of HFI and the patient's age in both male and female acromegalics (Table IV). This trend was not apparent in the control group. A similar, though less marked, relationship was found between the severity of HFI and the duration of acromegaly, but only in the female acromegalic patients. 
Table III Expression of moderate and severe HFI in acromegaly and in acromegaly associated with hyperprolactinaemia when compared to controls

\begin{tabular}{|c|c|c|c|c|c|}
\hline $\begin{array}{l}\text { Skull X-ray } \\
\text { value }\end{array}$ & & Normal & $\begin{array}{c}\text { HFI } \\
\text { (mod./ } \\
\text { severe) }\end{array}$ & $\begin{array}{c}\text { Chi } \\
\text { square }\end{array}$ & $P$ \\
\hline Acromegaly & : Total & 20 & 16 & 11.47 & 0.0007 \\
\hline Control & : Total & 27 & 1 & & \\
\hline Acromegaly & : Male & 6 & 4 & 4.15 & 0.0417 \\
\hline Control & : Male & 14 & 0 & & \\
\hline Acromegaly & : Female & 4 & 12 & 11.37 & 0.0007 \\
\hline $\begin{array}{l}\text { Control } \\
\text { Acromegaly with }\end{array}$ & : Female & 13 & 1 & & \\
\hline hyperprolactinaemia & : Total & 3 & 9 & 19.21 & 0.0000 \\
\hline $\begin{array}{l}\text { Control } \\
\text { Acromegaly with }\end{array}$ & : Total & 27 & 1 & & \\
\hline hyperprolactinaemia & : Male & 1 & 2 & 5.13 & 0.0235 \\
\hline $\begin{array}{l}\text { Control } \\
\text { Acromegaly with }\end{array}$ & : Male & 14 & 0 & & \\
\hline hyperprolactinaemia & : Female & 2 & 7 & 9.14 & 0.0025 \\
\hline Control & : Female & 13 & 1 & & \\
\hline
\end{tabular}

Table IV Comparision of degree of HFI with patient age duration of illness

\begin{tabular}{lcccc}
\hline & Normal & Mild & Moderate & Severe \\
\hline $\begin{array}{l}\text { Mean patient age (years) } \\
\text { Male acromegalic }\end{array}$ & 50.2 & 54.8 & 63.75 & - \\
Male control & 55.6 & 48 & - & - \\
Female acromegalic & 51.5 & 53.8 & 61.9 & 78 \\
$\quad \begin{array}{l}\text { Female control } \\
\text { Mean illness duration (years) }\end{array}$ & 57.4 & 62.5 & 56.3 & - \\
$\quad$ Male acromegalic & 14.0 & 10.3 & 15.5 & - \\
Female acromegalic & 12.0 & 12.7 & 13.9 & 2 \\
\hline
\end{tabular}

\section{Discussion}

Acromegaly is characterized clinically by skeletal, skin and soft tissue overgrowth. ${ }^{5}$ These somatic features are caused by the growth-promoting actions of growth hormone which are thought to be mediated principally by the somatomedins, a group of insulin-like peptide growth factors. Acromegalic patients have been shown to have elevated somatomedin-C (insulin-like growth factor I) levels ${ }^{6}$ and it is postulated that this may be largely responsible for both the generalized, and the localized, skeletal overgrowth. However, somatomedins are probably not the sole cause of HFI. Insulin itself has been suggested as a causal factor in the new bone formation occurring in DISH. ${ }^{3}$ Growth hormone does have direct anti-insulin effects and induces both insulin resistance and hyperinsulinism. It is of note that, in DISH, no abnormality of either growth hormone or somatomedins has been discovered. ${ }^{7}$ In addition, Wolodzka, quoted by Littlejohn, ${ }^{3}$ studied 23 women with HFI and demonstrated normal basal growth hormone levels but elevated levels following glucose challenge. An additional hormonal influence on HFI may be mediated through PRL, but the mechanism of this effect is unknown. Hyperprolactinaemia has been shown to be associated with elevated levels of free testosterone, and dehydroepiandrosterone sulphate (DHAS) ${ }^{4}$ Although it is conceivable that both testosterone and DHAS will exert some influence on localized new bone formation, the elevation in androgen levels is minor in relation to the normal sex difference, and therefore it is unlikely that this is the causal mechanism.

The association of hyperprolactinaemia with acromegaly is relatively frequent and may be due to suprasellar extension of the adenoma, to stalk involvement or to dual growth hormone and PRL cell composition of the adenohypophyseal adenoma. ${ }^{8}$ The strong association of moderate and severe HFI with acromegaly and with hyperprolactinaemia suggests that HFI may be a further marker of pituitary dysfunction. HFI may, in 
addition, have some symptomatic significance. The retrospective nature of our study unfortunately precluded accurate recording of key symptoms such as headache. However, the association of headache with HFI is well established in the MSM syndrome. Headache also occurs in $50-87 \%$ of acromegalic patients $s^{5}$ and does not appear to correlate with tumour size, hormone levels, suprasellar extension, age, obesity or blood pressure. The persistence of headache after effective treatment of the pituitary adenoma may be due to the presence of HFI. As the headache of HFI is presumed to be due to bone overgrowth of the inner table of the skull, analgesia may potentially be achieved using those diphosphonate derivatives shown to have pain-relieving properties in Paget's disease.

\section{References}

1. Salmi, A., Voutilainen, A., Holsti, L.R. et al. Hyperostosis cranii in a normal population. Am J Roentgenol 1962, 87: $1032-1040$

2. Koev, D., Milanov, S., Koeva, L. \& Sirakova, V. Plasma growth hormone level in the Morgagni-Stewart-Morel syndrome. Endocrinologie 1978, 16: 65-68.

3. Littlejohn, G.O., Hall, S., Brand, C.A. \& Davidson, A. New bone formation in acromegaly: pathogenic implications for diffuse idiopathic skeletal hyperostosis. Clin Exp Rheumatol 1986, 4: 99-104.

4. Pawlikowski, M. \& Komorowski, J. Hyperostosis frontalis, galactorrhoea/hyperprolactinaemia and Morgagni-StewartMorel syndrome. Lancet 1983, i: 474.
In summary, HFI is strongly associated with acromegaly, both with and without hyperprolactinaemia. Its cause remains unknown but many factors are implicated. The presence of HFI may have symptomatic significance and its presence or absence should be established in all patients with acromegaly and hyperprolactinaemia.

\section{Acknowledgement}

We wish to thank Dr D.L. Davies, Western Infirmary and Dr E.H. McLaren, Stobhill General Hospital, for permitting the inclusion of their patients in our study.

5. Jadresic, A., Banks, L.M., Child, D.F. et al. The acromegaly syndrome. $Q J$ Med 1982, 202: 189-204.

6. Furlanetto, R.W., Underwood, L.E., Van Wyk, J.J. \& D'Ercole, A.J. Estimation of somatomedin-C levels in normals and patients with pituitary disease by radioimmunoassay. $J$ Clin Invest 1977, 60: 648-657.

7. Littlejohn, G.O., Herington, A.C. \& Smythe, H.A. Studies into various growth factors in diffuse idiopathic skeletal hyperostosis (D.I.S.H.) [Forestier's disease]. Rev Rheumatol 1981, 48: 987 (Abstract).

8. Melmed, S., Braunstein, G.D., Chang, R.J. \& Becker, D.P. U.C.L.A. Conference. Pituitary tumours secreting growth hormone and prolactin. Ann Intern Med 1986, 105: 238-253. 